\title{
VISSIM Simulation Parameter Checking Based on Time Headway Distribution
}

\author{
Ajay Kumar ${ }^{1}$, Dr. Vivek R Das ${ }^{2}$, BV Pramod ${ }^{3}$ \\ ${ }^{1}$ PG Student, Department of Civil Engineering, Dayanand Sagar College of Engineering Bangalore, Karnataka, India \\ ajaykumarchawni@gmail.com \\ ${ }^{2}$ Professor, Department of CTM, Dayanand Sagar College of Engineering Bangalore, Karnataka, India \\ vivekdurgadath@gmail.com \\ ${ }^{3}$ Assistant Professor, Department of CTM Dayanand Sagar College of Engineering Bangalore, Karnataka, India \\ ctm@dayanandsagar.edu
}

\begin{abstract}
The Transportation System be it in any country plays an important role in forming a sustainable development with reference to economic and social Stature of a country. Modelling the vehicular traffic in an efficient way especially in India have been a major concern due to its heterogeneous traffic condition. Microscopic traffic simulation models have got the better hand in modelling the heterogeneous traffic condition. VISSIM is been extensively utilized in the field of traffic operation, transportation management, designing and evaluating the performance before implementing the improved conditions in the realistic field condition. In this model decisions upon controlling and designing are controlled by their reliability and accuracy. This paper evaluates the driving performance parameters by selecting un - signalized which are been modeled by using VISSIM. Prior to modelling controllable and un - controllable input parameters have been defined. Simulation is been done for these input parameters by using the default parameters that VISSIM possess. These results concluded that the simulation which runs with default value was incapable in replicating the realistic field condition. In addition, these values resulted in larger queue lengths and travel time than observed in the test junctions. Thus calculable evaluation is performed by virtue of Iteration Analysis to discover the impact of the selected parameters. Further numbers of simulation runs were performed by changing the default values within the ranges specified by acknowledge the importance of balancing the parameters so that the INTERSECTIONS can be enhanced. Therefore, outcome received from the standardize models were comparable to those observed from the field data surveys. The simulation results using default parameters conveyed only 15 - 20\% similarity to the field condition, whereas the results obtained by iteration analysis matched nearly 70 - $80 \%$ of the field observed data. Finally these analysis proved that standardize driving performance parameters.
\end{abstract}

Keywords: Traffic Simulation, VISSIM, Driving Parameters, Iteration Analysis

\section{Introduction}

Micro - Scopic Traffic simulation models are well known for conducting a research in traffic engineering and transportation planning. Future of these models completely relies on the realistic representation of the traffic data they provide. The flexibility that the software offers in extracting all possible solutions for mobility related traffic problems as well as the tremendous savings in time and cost is regarded as the major advantage of Micro - Scopic Traffic simulation models. In many developing countries, absence of lane marking and lane discipline, haphazard movement at intersections and dis - organized movement of a variety mix of different vehicle types is commonly observed structure which makes it difficult to replicate using traditional analytical models. Hence creating a wide demand for micro scopic traffic simulation models. The efficiency as well as acceptability of this traffic simulation model in evaluating various scenarios rely on its ability to reflect the local driver characteristics, study area network and infrastructure.

VISSIM utilizes the Wiedemann 74 and Wiedemann 99 car following model for Diving Behavior analysis. This model contains ten modifiable car - following parameters $(\mathrm{CCO}-$ CC9) which represent four driving modes such as free driving, following approaching and braking. The main requirement was to gain a greater understanding in different driver behavior parameters and their interactive influence on capacity and its use in understanding the standardization processes. These studies mainly focused on the relationship ST between the capacity and each and every driving behavior parameters individually and cautiously examining into the driver behavior interactions with each the parameters. The parameters of the model that require standardization include traffic flow, traffic control operations and Driver behavior, Model authentication results are tested for their accuracy by comparing the generated data from simulation model to the data collected from the study area.

\section{Present Research}

The selection of the research area can be shortlisted based on the information which is to be required for the further model creation. HMT junction which is an un - signalized intersection which is showed below, and shortlisted to neglect incompatible of data on the respective selected measure of effectiveness i. e Travel - time, queue length etc 


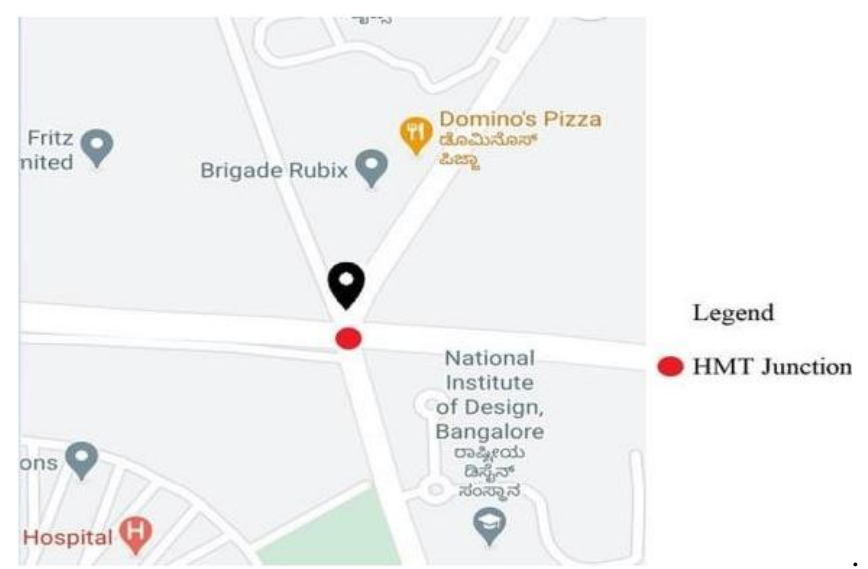

Figure 1: Study Area

\section{Data Collection}

Data of heterogeneous traffic flow such as data on turning vehicles movement, network geometry, vehicle mix, traffic volume data, spot speed studies, Queue length, travel time, were been collected using digital camera at selected study locations.

Table 1: Traffic Volume Count

\begin{tabular}{|c|c|}
\hline Timings & Traffic Flow \\
\hline 8: 00 - 9: 00AM & 4819 \\
\hline 9:00 - 10: 00AM & 5498 \\
\hline 10:00 - 11: 00AM & 4663 \\
\hline 11:00 - 12: 00AM & 3694 \\
\hline 4: $00-$ 5: 00PM & 3622 \\
\hline 5: $00-6: 00 \mathrm{PM}$ & 4618 \\
\hline 6: $00-7: 00 \mathrm{PM}$ & 8153 \\
\hline 7: $00-8: 00 \mathrm{PM}$ & 8109 \\
\hline
\end{tabular}

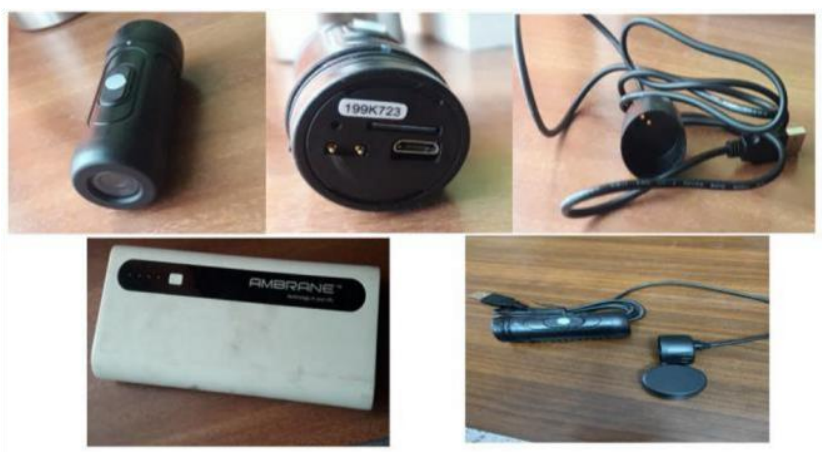

Figure 2: Video Recorder for Automatic Data Recording

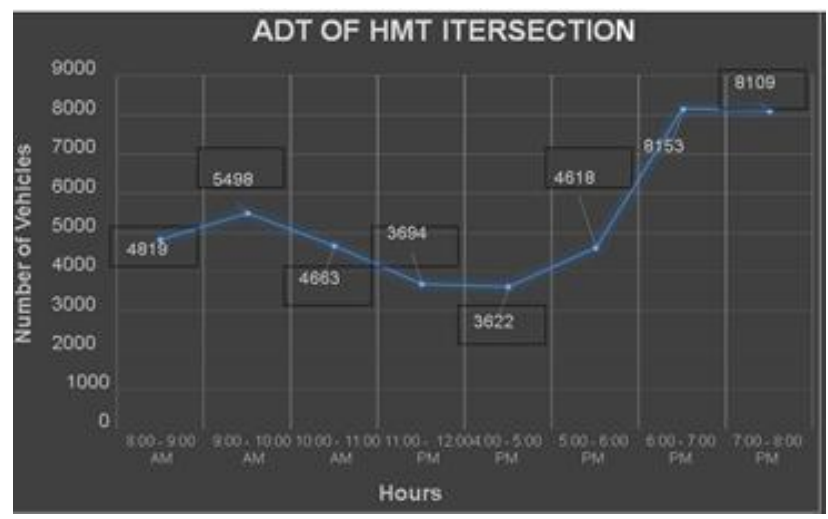

Graph 1: Traffic Volume Count

\subsection{Queue Length}

Table 2: Queue Length of Each Leg

\begin{tabular}{|c|c|c|}
\hline No. & Leg Name & Average queue length in $\mathrm{m}$ \\
\hline 1 & Brigade Rubix & 250 \\
\hline 2 & Ring Road & 100 \\
\hline 3 & Platinum City & 200 \\
\hline 4 & Peenya & 240 \\
\hline 5 & BFW & 110 \\
\hline
\end{tabular}

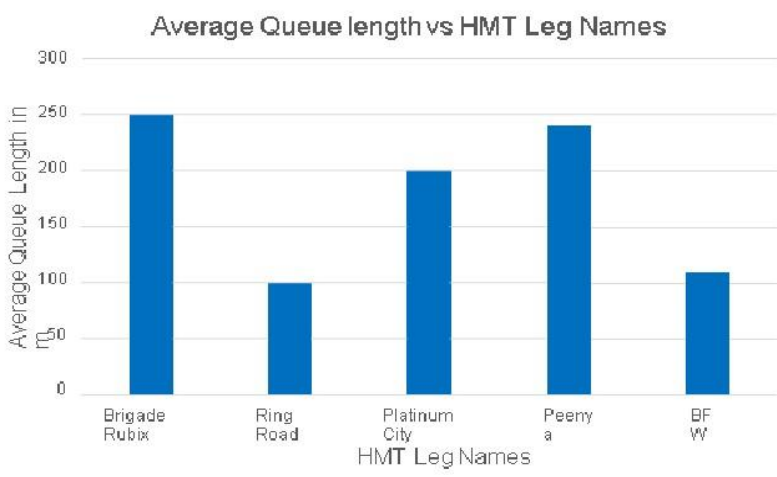

Graph 2: Average Queue Length Vs Leg Name

\subsection{Turning Moment Survey}

The Turning Movement Count is the count of pedestrians, cycles and vehicles that are moving towards the intersection The main aim is to collect the vehicle data to determine the traffic flow in that particular direction. Turning Moment Count is used to determine the right turn, left turn and thru traffic of fast moving vehicles. Turning Moment Count is done for 12 hours i. e. from morning 8: 00 to evening 8: 00 with a time

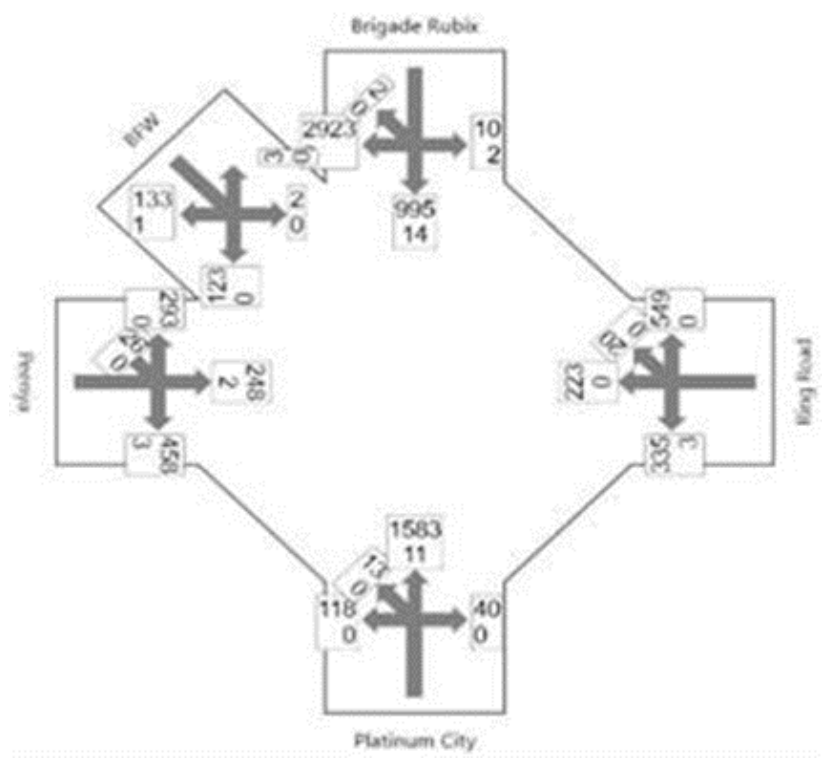

Figure 3: Turning Moment Using Sidra 


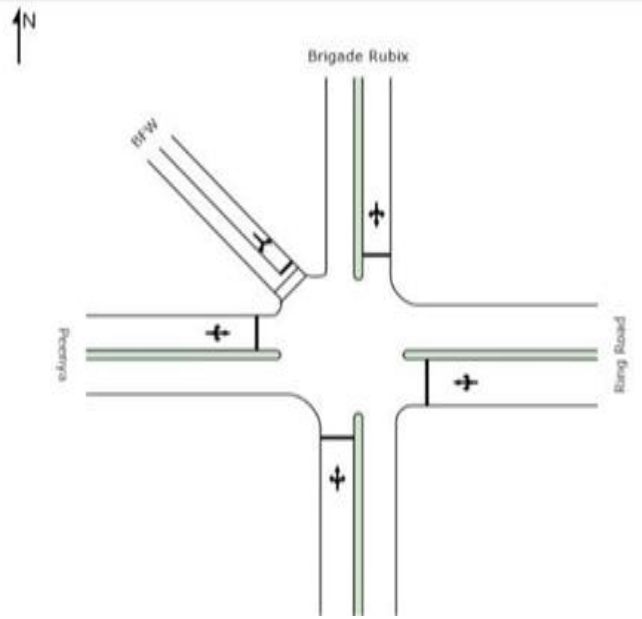

Figure 4: HMT Intersection Using Sidra

\subsection{Road Geometric Studies:}

Road Geometry Studies is a branch of the Highway components according to the standards and constraints
- Cross - section

- Intersection
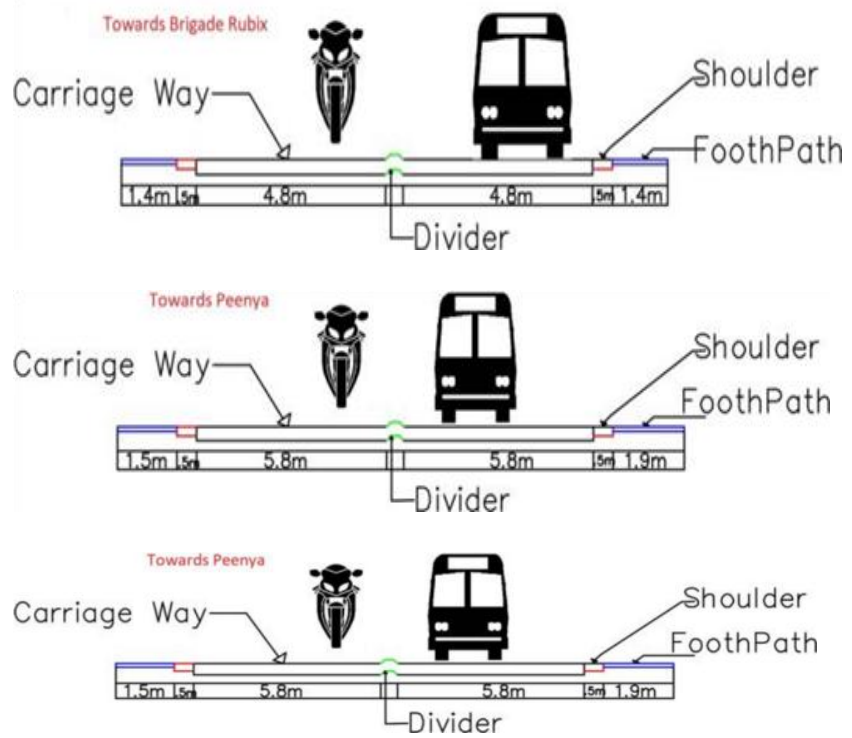

This includes:

- Alingment

- Profile

\begin{tabular}{|c|c|c|c|c|c|c|c|}
\hline \multirow{2}{*}{ Leg Name } & Width of & \multicolumn{2}{|c|}{ Width of Lane (m) } & Length of & Shoulder & \multicolumn{2}{|c|}{ Footpath (m) } \\
\cline { 3 - 4 } \cline { 6 - 8 } & Road (m) & Left & Right & Divider $(\mathrm{mm})$ & $(\mathrm{m})$ & Left & Right \\
\hline Platinum City & 10 & 5 & 5 & 38 & 0.5 & 1.8 & 4 \\
\hline Peenya & 11.6 & 5.8 & 5.8 & 1500 & 0.5 & 1.5 & 1.9 \\
\hline BFW & 6 & 0 & 0 & No Divider & 0.5 & \multicolumn{2}{|c|}{ No Footpath } \\
\hline Brigade Rubix & 9.6 & 4.8 & 4.8 & 200 & 0.5 & 1.4 & 1.4 \\
\hline Ring Road & 16.4 & 8.2 & 7.8 & 800 & 0.5 & 1.2 & 1.2 \\
\hline
\end{tabular}

Figure 7: Jucation Details

\subsection{Spot Speed Studies}

- Spot Speeds are referred as the instantaneous speeds of vehicles at a cross section.

- Spot Speed Studies are generally conducted to determine the speed variation of traffic system at particular point.

- Data collected from this studies are used to determine the speed percentile i.e. upper speed percentile, lower speed percentile and design speed percentile which in turn describes various speed related decisions.

This studies provides the measure of effectiveness of traffic control devices, signs and markings.
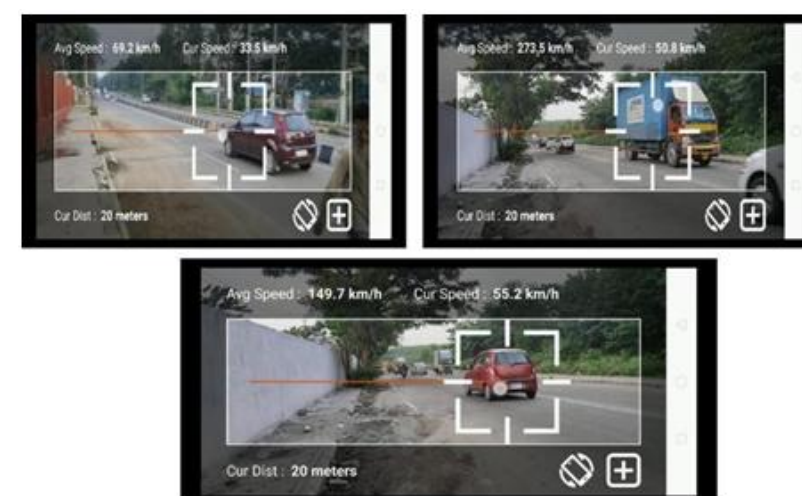

Figure 8: Field pictures

Table 4: Spot speed details

\begin{tabular}{|c|c|c|c|c|}
\hline \multicolumn{2}{|c|}{ From Brigade Rubix } & & \multicolumn{2}{c|}{ Timings 9:00 AM-10:00AM } \\
\hline Speed Range & $\begin{array}{c}\text { No. of } \\
\text { Vehicles }\end{array}$ & $\begin{array}{c}\text { Mid Speed } \\
\text { (Kmph) }\end{array}$ & \% Frequency & $\begin{array}{c}\text { Cumulative } \\
\text { Frequency }\end{array}$ \\
\hline $0-10$ & 190 & 5 & 7.9 & 7.9 \\
\hline $10-20$ & 410 & 15 & 17.2 & 25.1 \\
\hline $20-30$ & 820 & 25 & 34.4 & 59.5 \\
\hline $30-40$ & 655 & 35 & 27.5 & 87 \\
\hline $40-50$ & 250 & 45 & 10.5 & 97.5 \\
\hline $50-60$ & 58 & 55 & 2.5 & 100 \\
\hline $60-70$ & 0 & 65 & 0 & 100 \\
\hline $70-80$ & 0 & 75 & 0 & 100 \\
\hline $80-90$ & 0 & 85 & 0 & 100 \\
\hline Total & 2383 & & & \\
\hline
\end{tabular}



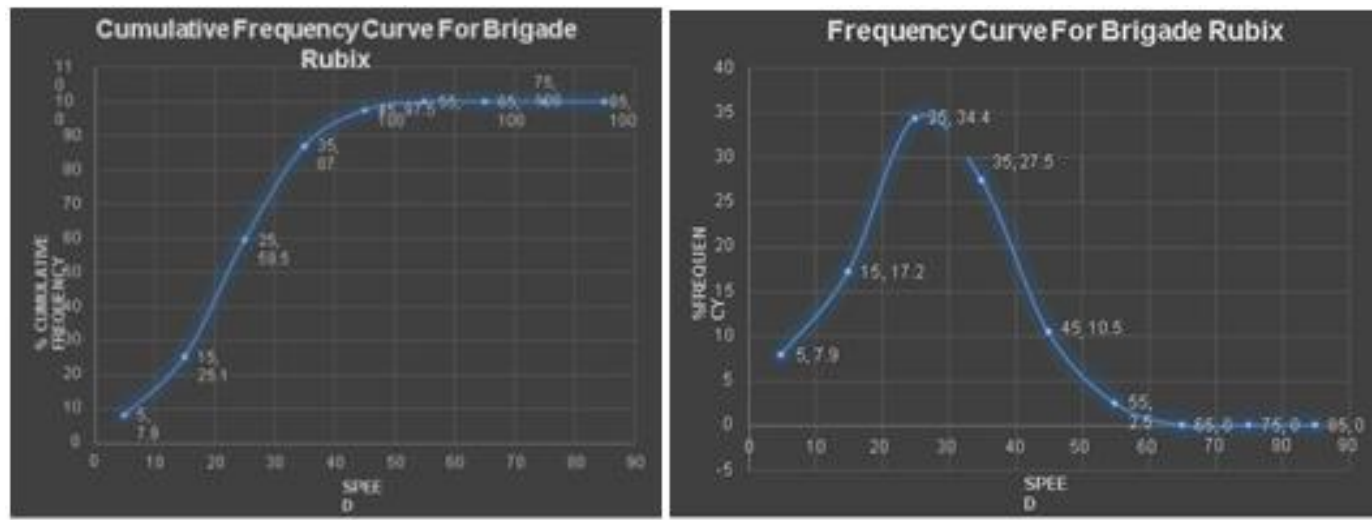

Upper Speed : $85 \%$ speed $=34 \mathrm{~km} / \mathrm{h}$

Lower Speed: $15 \%$ speed $=10 \mathrm{~km} / \mathrm{h}$

Design Speed: $98 \%$ speed $=45 \mathrm{~km} / \mathrm{h}$

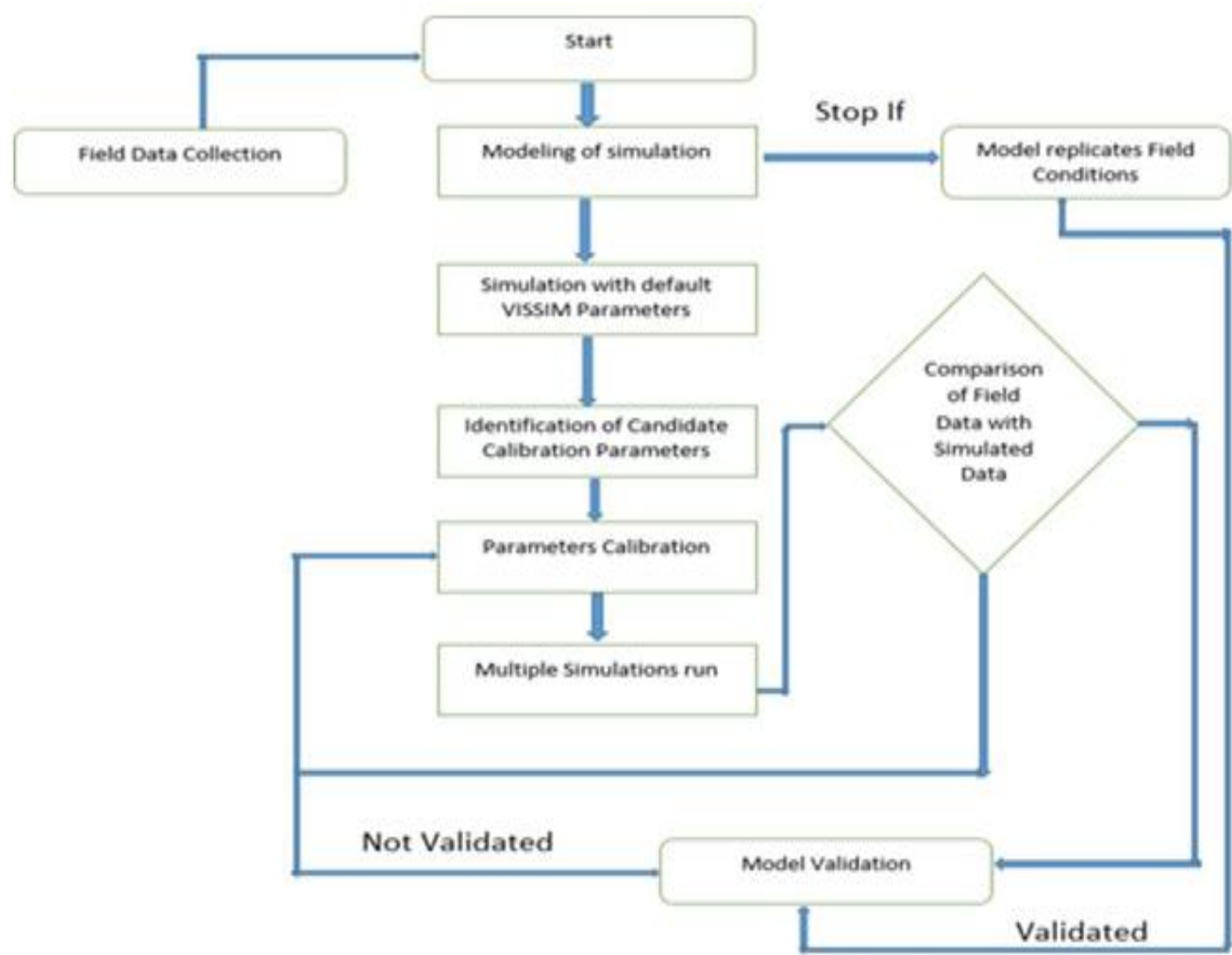

Figure 9: Flow Diagram of Software Analysis

The results of calibration and literation analysis from the various simulation runs for the parameters for HMT intersection are as mentioned below:

\section{Software Analysis}

Iteration Analysis 1: Maximum Look Ahead Distance

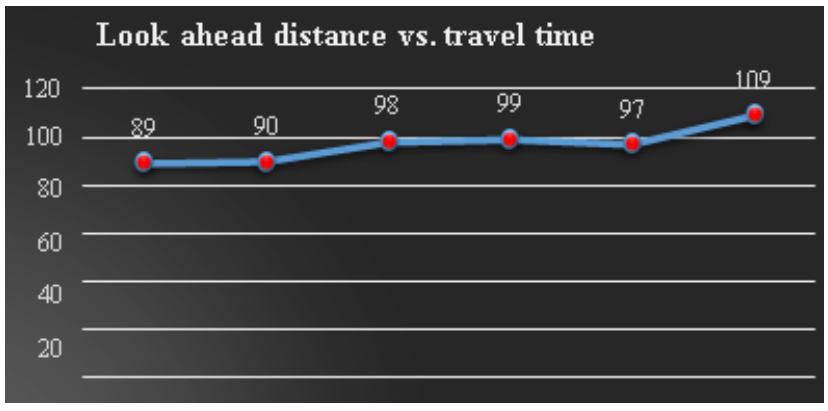

Graph 3: Look ahead distance vs Queue length 


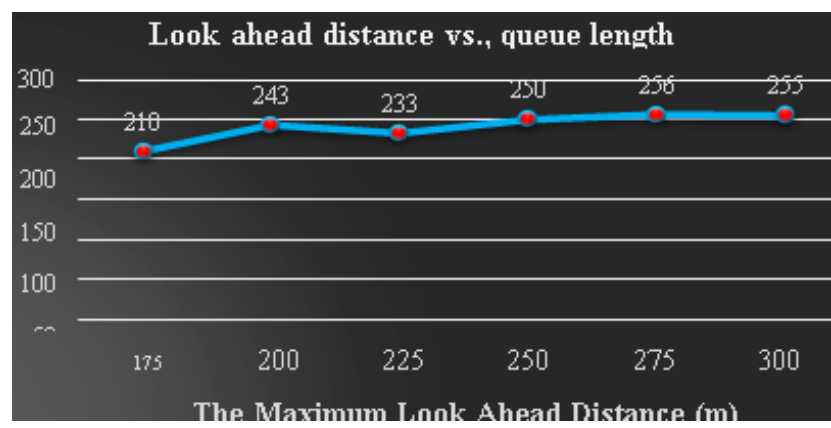

Graph 4: Look ahead distance vs Travel time

We can be drawn from Table and Figure that, changes in the maximum look ahead distance have considerable impact on the queue length at HMT intersection, but have significant impact on the travel time. For the maximum look ahead distance parameter value $250 \mathrm{~m}$ replicates the field value. Thus the value for maximum look ahead distance of $250 \mathrm{~m}$ is selected for further authentication.

\section{Iteration Analysis 2: Standstill Distance}

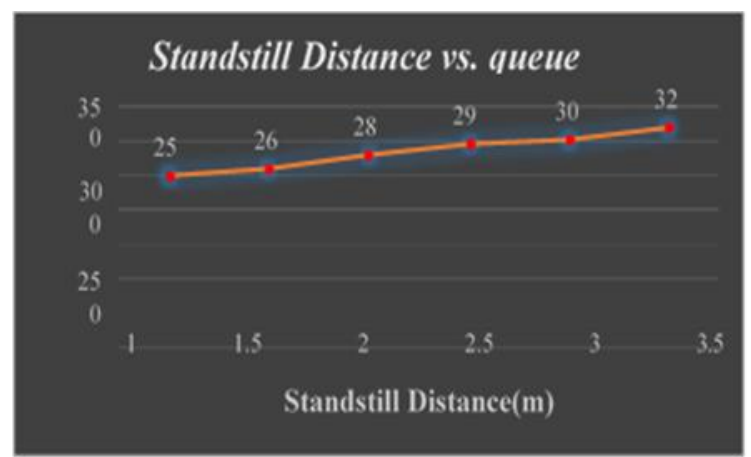

Graph 5: Standstill distance vs Queue length

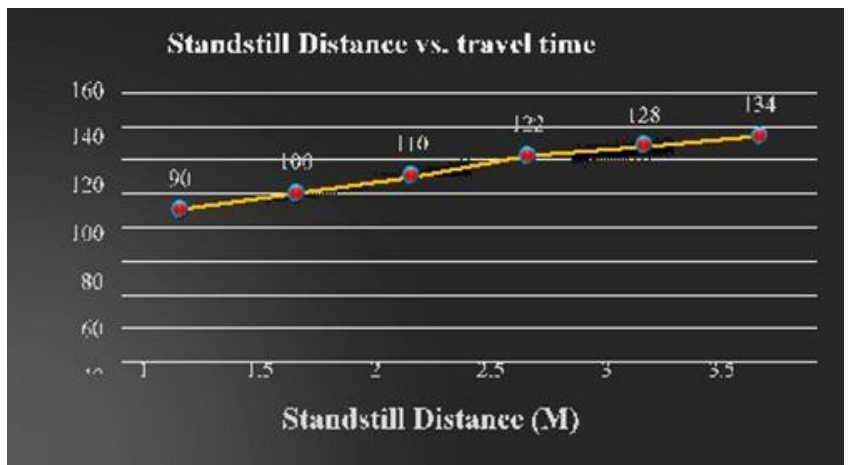

Graph 6: Standstill distance vs Travel time

The above graph's indicates that, varying the standstill distance has an impact on the queue length, and also inversely has impact on the travel time and the value considered for the future authentication is $2 \mathrm{~m}$.

\section{Iteration Analysis 3: Maximum Deceleration}

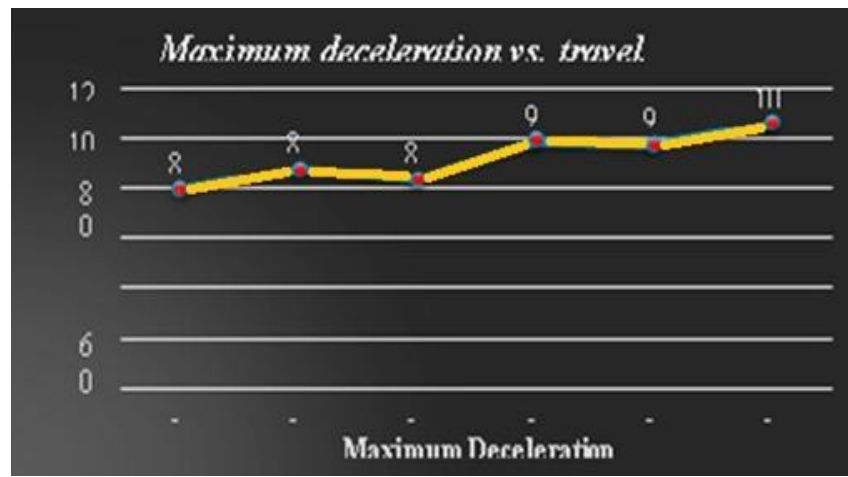

Graph 7: Maximum deceleration vs Queue length

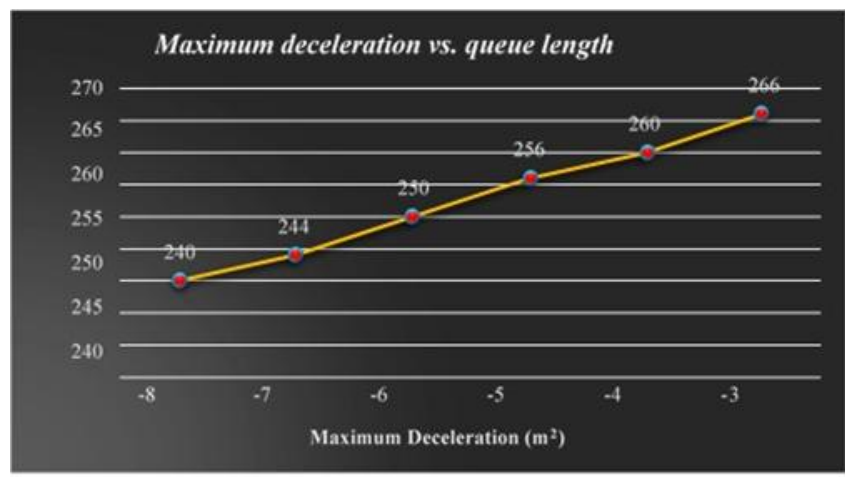

Graph 8: Maximum deceleration vs travel time time

The above graph's indicates that, varying the maximum decelerations has reasonable impact on the queue length, and has an high impact on the travel time and the value considered for the future authentication is $-5 \mathrm{~m}^{2}$.

\section{Iteration Analysis 4: Acceptance Deceleration}

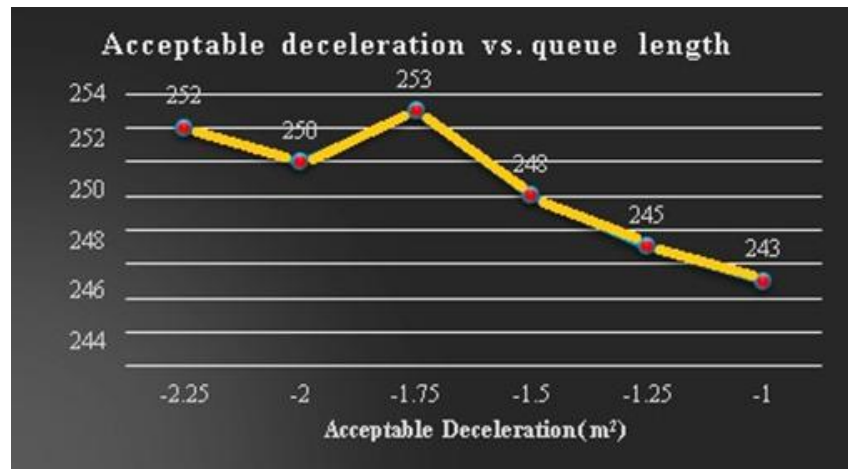

Graph 9: Acceptance decelerations VS Queue length

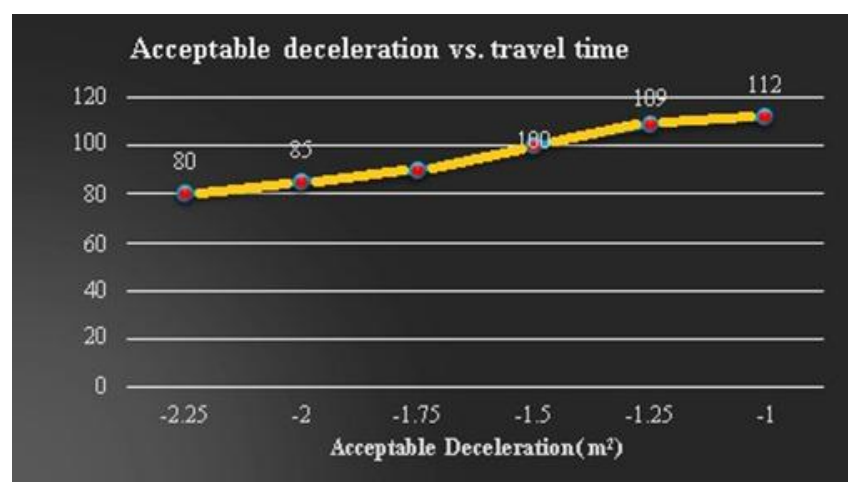

Graph 10: Acceptance deceleration vs travel time 
The above graph's indicates that, varying the acceptable deceleration has no impact on the queue length, but inversely has high impact on the travel time and the value considered for the future authentication is $-1.5 \mathrm{~m}$

\section{Iteration Analysis 5: Wait time before diffusion}

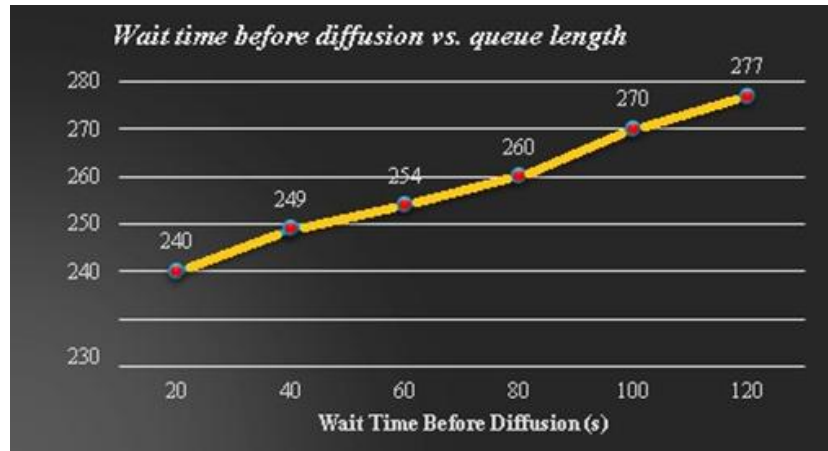

Graph 11: Waiting time before dissusion vs Queue length

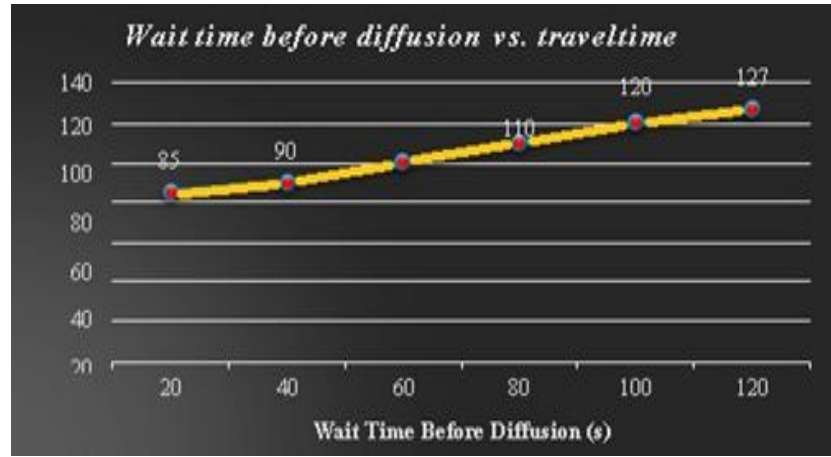

Graph 12: Waiting time before diffusion vs Travel time

The above graph's indicates that, varying waiting time before diffusion has a reasonable impact on the queue length, and inversely has greater impact on the travel time and the value considered for the future authentication is $60 \mathrm{sec}$

\section{Iteration Analysis 6: The minimum headway}

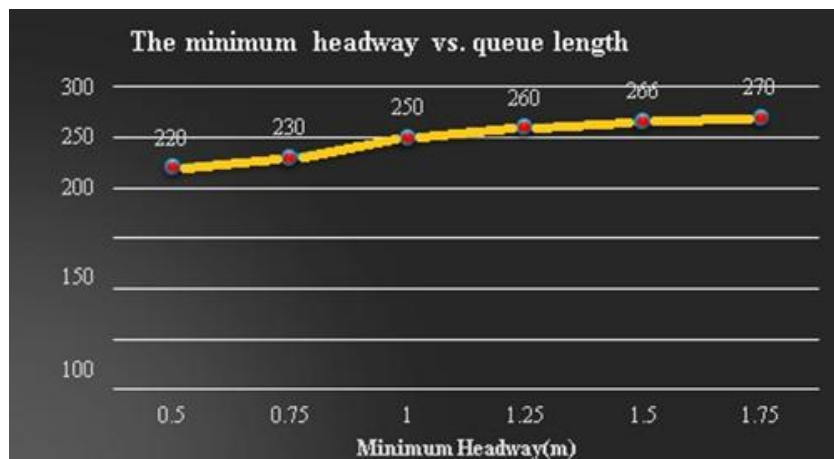

Graph 13: Minimum Headway vs Queue length

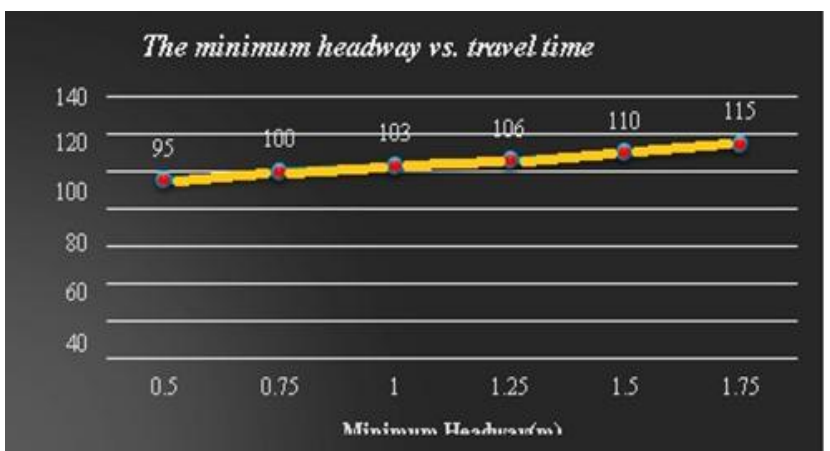

Graph 14: Minium head way vs Queue length

We can be drawn from Table and Figure that, changes in the minimum headway have a greater influence on both queue length as well as travel time at HMT intersection. For the minimum headway parameter value $0.75 \mathrm{~m}$ and $1 \mathrm{~m}$ replicates the field value for travel - time and queue length respectively. Thus the value for minimum headway of $0.75 \mathrm{~m}$ is selected for further authentication

\section{Iteration Analysis 7: Headway time}

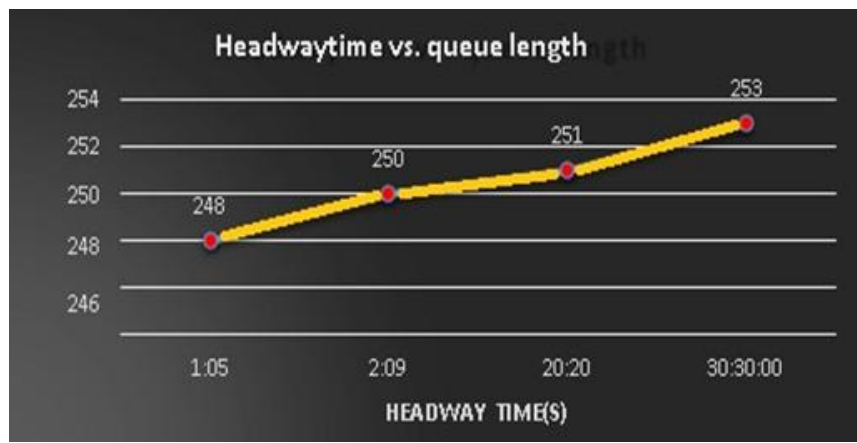

Graph 15: Headway vs Queue length

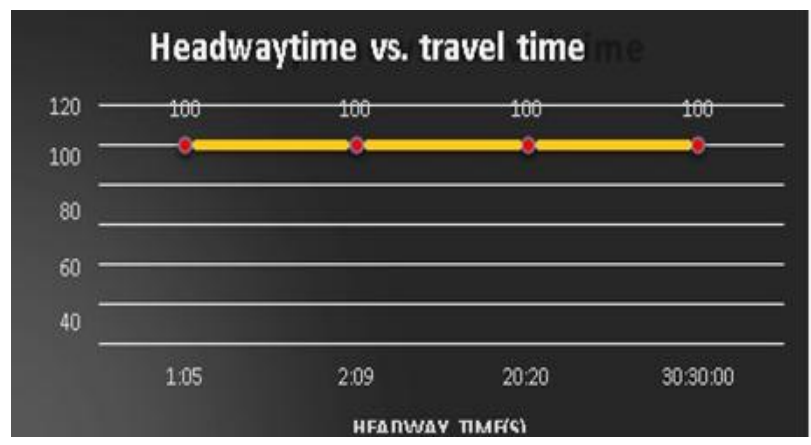

Graph 16: headway vs Travel time

We can be drawn from Table and Figure that, changes in the headway time has zero impact on the queue length as well as travel time at HMT intersection. For the headway time parameter value 2: 09s replicates the field value for both travel time and queue length. Thus the value for headway time of 2: 09s is selected for further authentication.

\section{Standardization and Authentication}

\section{Standardization procedure}

Simulating the network using VISSIM default value showed that the performance measure was not satisfying the field observed measure of effectiveness. Standardization is a process by which the selected driving behavior parameters 
that are adjusted to the realistic field data by performing Iteration Analysis so that it represents the real traffic condition. These standardize parameters were been adjusted to field data by performing number of iterations within the specified value ranges until the field values is similar to the VISSIM generated values for travel time and queue length. Hence these set of standardize parameters that are described in the table are further used for authentication process

Table 5: VISSIM Standardize and Default Values of HMT Junction

\begin{tabular}{|c|c|c|c|}
\hline $\begin{array}{c}\text { Classification } \\
\text { Number }\end{array}$ & Description of Parameters & $\begin{array}{c}\text { Default } \\
\text { value }\end{array}$ & $\begin{array}{c}\text { Standardize } \\
\text { Value }\end{array}$ \\
\hline 1 & The Maximum Look AheadDistace $(\mathrm{m})$ & 250 & 250 \\
\hline 2 & Standstill distance $(\mathrm{m})$ & 1.5 & 1 \\
\hline 3 & Additional parts of the safety distance $/ \mathrm{m}$ & 2 & 2.5 \\
\hline 4 & Multiple parts of the safety distance $/ \mathrm{m}$ & 3 & 5 \\
\hline 5 & Maximum deceleration $/ \mathrm{m}^{\wedge} 2$ & -4 & -5 \\
\hline 6 & Acceptable deceleration $/ \mathrm{m}^{\wedge} 2$ & -1 & -2 \\
\hline 7 & Wait time before disappearing / & 60 & 40 \\
\hline 8 & The minimum headway / $\mathrm{m}$ & 0.5 & 0.75 \\
\hline 9 & Headway time $(\mathrm{s})$ & $2: 09 \mathrm{~s}$ & $2: 09 \mathrm{~s}$ \\
\hline
\end{tabular}

These parameters were been identified as the best because of its yielded performance measure satisfied the required criteria. Average travel time and average queue length obtained using these standardize parameters was close replications of the field measure of effectiveness. Hence the next step was to validate these standardize parameters.
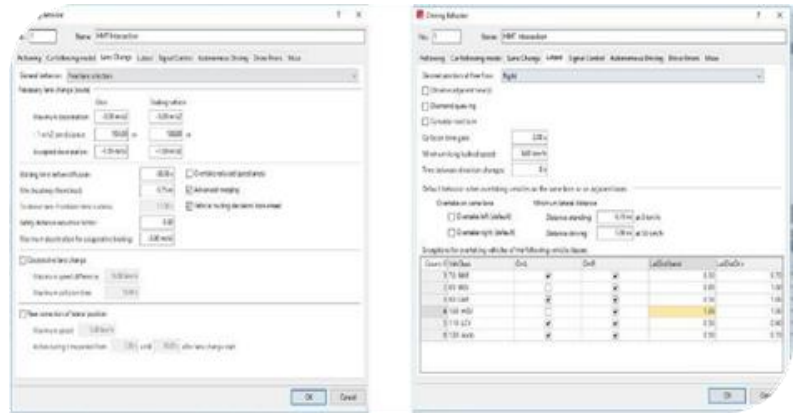

Figure 10: HMT car - following details
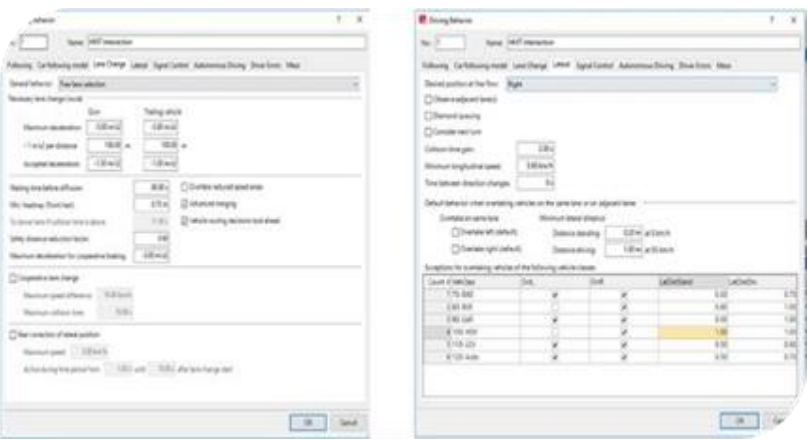

Figure 11: HMT lane changing and lateral details

\section{Model Authentication}

For HMT Junction, Brigade Rubix road connecting Ring Road, Platinum City, Peenya and BFW road has been used for authentication analysis.

\section{Existing HMT Junction:}

Table 6: HMT Queue length Authentication Results

\begin{tabular}{|c|c|c|c|}
\hline Junction & $\begin{array}{c}\text { Default Value } \\
(\mathrm{m})\end{array}$ & $\begin{array}{c}\text { Field } \\
\text { Value }(\mathrm{m})\end{array}$ & $\begin{array}{c}\text { Standardize } \\
\text { Value }(\mathrm{m})\end{array}$ \\
\hline Brigade Rubix & 250 & 310 & 250 \\
\hline Ring Road & 100 & 200 & 110 \\
\hline
\end{tabular}

\begin{tabular}{|c|c|c|c|}
\hline Peenya & 240 & 300 & 230 \\
\hline Platinum City & 200 & 240 & 240 \\
\hline BFW & 110 & 160 & 120 \\
\hline
\end{tabular}

Table 7: HMT Travel time Authentication details

\begin{tabular}{|c|c|c|c|}
\hline Junction & $\begin{array}{c}\text { Default } \\
\text { Value (s) }\end{array}$ & $\begin{array}{c}\text { Field Value } \\
(\mathrm{s})\end{array}$ & $\begin{array}{c}\text { Standardize } \\
\text { Value (s) }\end{array}$ \\
\hline Brigade Rubix & 100 & 98 & 100 \\
\hline Ring Road & 45 & 55 & 50 \\
\hline Peenya & 80 & 99 & 82 \\
\hline Platinum City & 98 & 110 & 100 \\
\hline BFW & 88 & 80 & 90 \\
\hline
\end{tabular}

Result from Iteration Analysis and Authentication:

Measure of effectiveness (MOE) generated from the VISSIM using default value of the parameters i. e. un standardize parameters and those obtained by the standardize parameters proved the need and importance of the standardization and its authentication. As described in the table and figures the models that are standardize, replicated the realistic field data better than that of un - standardize models. These un - standardize models indicated higher speeds, larger queue length, and short travel time when compared to that of observed field data.

For the travel time analysis the range of values change was somewhere between $15 \%$ when default values were used and $5 \%$ range of value changes when the standardize parameters was used. Travel time at HMT junction, Brigade Rubix to Platinum City had a maximum of $15 \%$ difference when compared to the remaining legs and minimum difference of $0.9 \%$ for the Ring Road leg. Queue length for HMT junction was comparable and accountable for 6-12\% difference that of field observation. Therefore all the MOEs used for authentication had a range of change of values was between $5-10 \%$ to that of field observed values. This indicated the importance of the appropriate model standardization with all selected parameters for HMT network.

\section{Improvements for HMT junction:}

- A separate lane approaching should be provided from Bridge Rubix including a separate median so that it should differentiate the right moving traffic and the left including thru moving traffic for the junction. 
- Similarly the same should be provided for the lane which is approaching from the platinum city and peenya

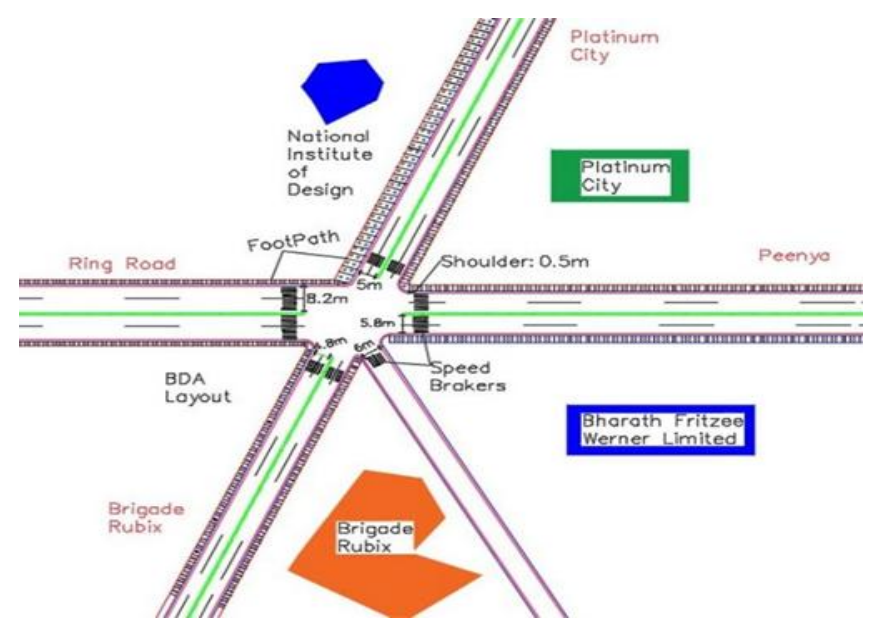

Figure 12: Improved HMT junction

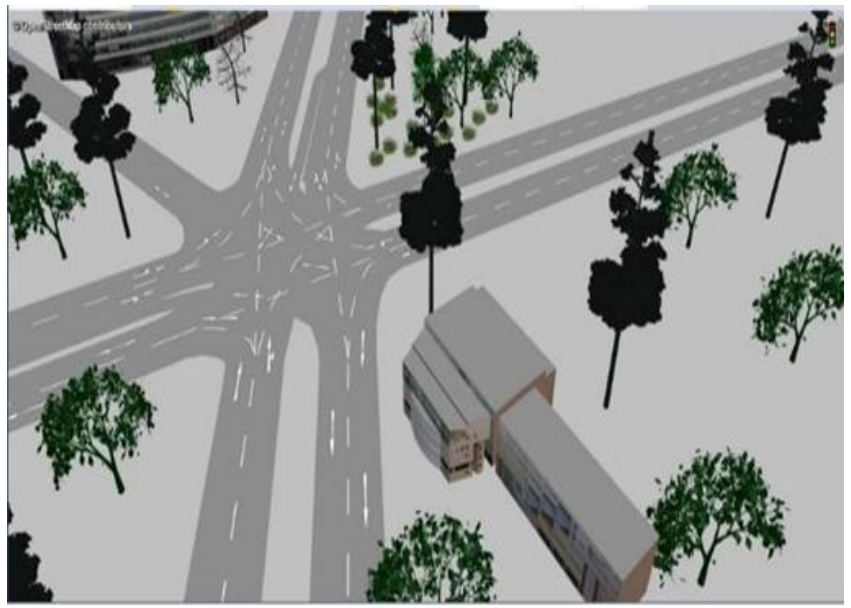

Figure 13: Improved HMT juncation in VISSIM

\section{Conclusion}

1) The standardization and the authentication of the HMT Junction was been demonstrated through the microscopic simulation models in the view to find out the optimal values for microscopic driving behavior parameters.

2) The proposed methodology which is adopted for the standardization and authentication of VISSIM software was found to be effective for the signalized intersection but slighter in effective in the case of un - signalized intersection i. e. HMT intersections.

3) It concluded that the VISSIM micro - simulation models which runs with the default parameter value was not capable of replicating the realistic field conditions.

4) The iteration analysis of the VISSIM driver behavior parameters for the car following, lane changing and lateral movement models on the safety was simulated and their impact in the analysis was demonstrated.

5) Hence the influential driver behavior parameters which impact the safety as well as the operations were been identified and standardize.

6) The parameter that are standardize was able to enhance the precision of the measure of effectiveness considerably.
7) The un - standardize models resulted in larger queue lengths as well as shorter travel time than that of observed in the field.

8) The authentication results of the standardize parameters for the traffic conditions on the Brigade Rubix road demonstrated the adequacy of the standardize parameters.

9) The authentication of standardize models was been analyzed with the data arrived from the iteration analysis.

10) Sidra Intersection software was been used to analyze the turning moment for the intersections as well as to design the intersections for both existing and improved conditions.

11) Therefore from the process of the standardization and authentication for HMT road network, this analysis was capable in identifying some of the important driving behavior parameters which can be used as benchmark for further studies to simulate the different scenarios in VISSIM prior to the field implementation.

\section{Scope for future studies}

- To check all the standardize driving behavior parameters whether it can be utilized for the roundabouts or if it is only applicable for a particular intersection.

- It can also be recommended to utilize the remaining performance measure such as delays, stops, emissions and fuel consumption for authentication.

- The standardization and authentication for the walking behavior of the pedestrians is recommende

\section{References}

[1] A. C. Dey, M. A. Uddin \& S. Roy, December 2018. Standardization And Authentication Of Vissim Model Of An Intersection With Modified Driving Behaviour Parameters. International Journal Of Advanced Research, vol 6 (2), pp.107 - 112.

[2] M. Hassan, et al., 28 May 2019. Using Microscopic Simulation - Based Analysis to Model Driving Behaviour: A Case Study of Khobar - Dammam in Saudi Arabia, Saudi Arabia: MDPI.

[3] Habtemichael, F. \& Santos, L. d. P., January 2013. Iteration Analysis Of Vissim Driver Behaviour Parameters On Safety Of Simulated Vehicles And Their Interaction With Operations Of Simulated Traffic. Libson, Research Gate.

[4] Gallelli, V. \& Vaiana, R., 2008. Roundabout Intersections: Evaluation Of Geometric And Behavioural Features With Vissim, Kansas: Transportation research board.

[5] Siddharth \& Ramadurai, G., 2013. Standardization of VISSIM for Indian Heterogeneous Traffic Conditions. Elsevier Ltd., pp.380 - 389.

[6] Lownes, N. E. \& Machemehl, R. B., 2006. Iteration of Simulated Capacity to Modification of VISSIM Driver Behaviour Parameters. The international journal of transportation research, pp.102 - 110 . 
[7] Richter, M. \& Paszkowski, J., 2018. Modelling driver behaviour in traffic - calmed areas. Volume 8, pp.111 124.

[8] Fransson, E., 16 Feb 2018. Driving behaviour modeling and evaluation of merging control strategies A microscopic simulation study on Sirat Expressway, Sweden: Linkoping University.

[9] Yannes, C. D. \& Lownes, N. E., 2010. Driver behaviour considerations in calibrating microsimulation models for capacity. Int. J. Society Systems Science, vol 2 (1), pp.8499.

[10] Maheshwarya, P., Bhattacharyya, K., Maitra, B. \& Boltze, M., 15 July 2016. A methodology for standardization of vehicle class - wise driving behaviour in heterogeneous traffic environment, Kolkata: Science Direct.

[11] Raju, N., Arkatkar, S. \& Joshi, G., 2019. Methodological Framework for Modeling Following Behaviour of Vehicles Under Indian Traffic Scenario, Surat: Innovative research in transporation infrastructure.

[12] Lu, Z., Fu, T., Fu, L. \& Jiang, S. S. a. C., 17 May 2016. A Video based approach to calibratng car following parameters in vissim for urban traffic. International journal od transporation science and technology, Volume 5, pp.1 - 9.

[13] Mehar, A., Chandra, S. \& Velmurugan, a. S., 2014. Highway Capacity Through Vissim Standardize for Mixed Traffic Conditions. KSCE Journal of Civil Engineering, 18 (2), pp.639 - 645.

[14] Viti, F., Hoogendoorn, S. \& Arem, B. v., July 2010. Microscopic data for analysing driving behaviour at traffic signal, Netherlands: Research Gate.

[15] Edara, P. \& Chatterjee, I., 7 Sept 2013. Multivariate regression for estimating driving behaviour parameters in work zone simulation to replicate field capacities. The International Journal of Transportation Research, 2 (3), pp.175 - 186.

[16] Chen, C., Zhao, X., Ren, G. \& Liu, X., 5 Feb 2019. Assessing the Influence of Adverse Weather on Traffic Flow Characteristics Using a Driving Simulator and VISSIM. MDPI, pp.1 - 16.

[17] Higgs, Abbas \& Medina, 2014. Analysis of the Wiedemann Car Following Model over Different Speeds using Naturalistic Data, s. 1.: Virginia Tech.

[18] Niezgoda, M., Kamieski, T. \& Kruszewski, M., 2012. MEASURING DRIVER BEHAVIOUR INDICATORS FOR TRAFFIC SAFETY. Journal of KONES Powertrain and Transport, 19 (4), pp.503 511.

[19] Suresh, A. \& Rajbongshi, P., January - March 2016. Traffic Simulation and Standardization of Heterogeneous Traffic by VISSIM. Journal of Civil Engineering and Environmental Technology 3 (4), pp.308 - 311.

[20] Liu, W., Qin, Y., H. D. \& Yang, Y., 2014 - 09 - 02. Driving behaviour parameter iteration analysis based on VISSIM. Trans Tech Publications, Volume 668 669 , pp. $1453-1457$ 